\title{
Energy Technology Exploration of Element Power Transmission and Distribution System
}

\author{
Minghao Zhang \\ Branch of Electric Power Transformation \\ Liaoning State Grid Electric Power Transmission \& Transformation Engineering Company \\ Shenyang, China \\ zhangminghao2008@126.com
}

\begin{abstract}
This paper studies the carbon fiber structure, physical properties, chemical properties as well as classification of the carbon fibers and the application of carbon fiber, through appropriate material selection (the merits of the material), a large number of experiments (of manufacturing a heating element) and an accurate analysis of the experimental results, we have successfully combine the electrical properties of carbon fiber and soft performance of insulation materials, developed a body which can be used for people to make a variety of heating, insulation clothes, gloves, knee pads and insoles and other products, some products just over a year sales and marketing, and achieved good economic and social benefits. Practice has proved, the product have good heat insulation properties of the product, the product technology is advanced, mature production technology can be widely used in all aspects of production and life, upon retrieval of the item product technology for domestic initiative.
\end{abstract}

Keywords- structure; properties; experiments; benefits; practice

\section{INTRODUCTION}

Now the construction and development of power system automation more perfect use the latest computer technology. The traditional substation video monitoring system subject to the limitations of technology development, only on-site monitoring, simple alarm information transmission, can not achieve long-distance transmission of video signals for this industry substation, the remote, real-time monitoring system is the safe operation of the industry essential prerequisite. For conventional unmanned substations for: long unattended and geographically distributed widely, all equipment must be able to adapt to environmental changes. Usually install important and expensive equipment. Monitoring, remote control, security, fire protection and alarm systems need to combine networking. The existence of the physical properties of high temperature, high pressure, high magnetism. Substations typically have better network bandwidth resources [1].

Power systems, power plants, natural primary energy into electrical energy to power the remote user to send electricity transmission lines in order to reduce energy loss and line impedance voltage drop, the voltage is increased need; To meet the power user security needs, but also to reduce the voltage, and assigned to individual users, which need to be able to raise and lower voltage, and to the distribution of power substation. So substation power system voltage through its transformation, receiving and distributing power electrical devices, it is linked power plants and power users of the middle part, through the substation voltage level of the grid will be linked, substation the role is to transform voltage, transmission and distribution of electricity.

Substation changes the voltage of the place. Sent to the power plant in order to power transmission to distant places, the voltage must be increased, into high-voltage, to a voltage near the user then need to reduce this work by elevating voltage substation to complete. The main device is a switch and transformer substation. Different size, small is called substation. Substation: generally $110 \mathrm{KV}$ substation voltage levels down below; substation: including various voltage levels substation.

Any construction process must follow certain principles problems especially Transmission and Distribution of Electrical Engineering in the engineering design process, first make sure the design of the substation can be long-term reliable power supply for the load, because the substation relatively long operating cycle, while the design process must follow the relevant legal provisions and the relevant provisions of the national systems "to the country's economic construction guidelines to point to further implement the economic policy of the country and the basic construction procedures, integrated use of systems engineering approach from the overall situation, properly handle the production and life, the relationship between security and economic aspects, accelerate the comprehensive and efficient use of resources, energy conservation and land resources for electricity production process major change electrical substation equipment and thematic projects must be sure to ensure its reliability[2]. Design work is the key to the construction of! Do designs work on the project construction period of quality investment costs and put into operation after the safety and reliability of the overall economic efficiency and productivity plays a decisive role.

\section{POWER TRANSMISSION AND DISTRIBUTION SYSTEM NECESSITY APPLICATION OF ENERGY SAVING TECHNOLOGIES}

A. Necessity

Power Transmission and Distribution system is composed of a transmission line with a variety of components, each component of the line and there is 
resistance when the current flows through the circuit and components will have some power loss, the loss is the loss of the line change. The so-called line loss becomes actually refers to the power loss in power transmission and distribution lines and circuit components generated in the operation, this loss is fixed loss has nothing to do with the change in charge, because of the loss caused by mismanagement and transformers and other equipment in losses arising from the operation of the variable loss if the loss is greater than the total amount of these losses amount within the specified range, then the most likely cause of power transmission and transformation system part of the equipment damage, so the application of energy-saving reduction in electricity transmission and distribution circuits consumption technology is particularly necessary, it is an effective way to reduce the power distribution circuit loss! Power Transmission and Distribution System in the running to take energy saving measures that can effectively improve the economic efficiency of power enterprises, has great significance for the further development of the electricity business [3]. From the industrial electricity and electricity perspective of people's lives, and the lives of industrial electricity consumption increased, and will inevitably increase the power transmission and transformation system running loss amount, taking energy saving measures, to a certain extent, Users can reduce the economic pressure electricity, saving electrical energy, is of great significance to the sustainable development of China's power industry.

\section{B. System Features and Benefits}

Easy installation: take full advantage of the power industry developed network environment, directly to the video server to access the network, without affecting the original network structure, easy to future system expansion. Monitoring front-end flexibility to choose any video capture device, the video server compressed into a digital signal transmission in the network. At the same time it can provide a variety of rich interface alarm equipment, temperature and humidity detection, infrared sensors and other devices to access functions. Fully meet the power industry indicators of environmental monitoring requirements. It is small, easy to install, using the embedded operating system, without staff, suitable for a variety of harsh environments.

Power industry system complexity, the number of points needs to be monitored more, scattered location, but also to achieve unified management. If you follow the traditional way, each one monitoring point needs professionals, management costs are high, and countless cabling projects is prohibitive. Albert world network video surveillance system, the successful resolution of decentralized control, centralized management problems. The network will connect all monitoring points into a system, the monitoring center to achieve unified management through a number of stations monitoring host. In addition, the World Albert unique proxy server effectively solved the video between different networks forwarding problem, easy to check the operation of the higher-ups of each plant through internet..
Powerful integrated software management system provides a wide control platform. Albert world of all network products can be managed on this platform. Set templates The video file retrieval and playback, image capture browsing, voice-way intercom function, alarm device management, PTZ control, user group management, electronic maps, log management. At the same time, a strong $\mathrm{R} \& \mathrm{D}$ team can ensure timely customized for specific requirements related to the function module power industry [4].

\section{POWER TRANSMISSION AND DISTRIBUTION SYSTEM LINE GOES LOSS RESEARCH}

Reactive power is also included as part of energy loss, but this is part of the energy loss by the resistance to electrical lines, copper wire winding transformer reactance transformer core being satisfied distributed in the form of magnetic energy. In addition, the line-to-ground capacitive branch, which not only do not consume reactive power, but also to inject reactive power line.

The reason the power generated in the transmission line losses in the following aspects:

a) Resistance effect: wire line, transformer, motor windings, the conductors are copper or aluminum material. When a current is passed, the current exhibits a resistance, this resistance is called the resistance of the conductor. Power transmission in the power network, must overcome the resistance of the conductor, resulting in a power loss, the loss is found in the heat conductor. Because this loss is caused by the resistance of the conductor, so called resistive losses, it is proportional to the square of the current, represented by formula. Winding losses in transformers, motors, etc., and used to call the copper loss.

b) Magnetic field: the need to establish and maintain the transformer alternating magnetic field, in order to boost or buck. Motors need to establish and maintain a rotating magnetic field, in order to operate and promote the production of mechanical work. Current build-up process of the magnetic field in the electrical equipment is the electromagnetic conversion process. In this process, due to the effect of the alternating magnetic field is generated in the iron core of electrical equipment in the hysteresis and eddy current, so that the core heat, resulting in a power loss. Because this loss is generated in the electromagnetic conversion process, so called excitation loss, it causes the core heat, often also known as iron loss [5].

c) The management of reasons: because of the management for the electricity sector and related personnel management are not strict, there are loopholes, resulting in illegal electricity users and stealing, leakage power components, power metering device and meter reading personnel missing copy error, the wrong copy, etc. The power loss caused. Because of this loss is no fixed rules, but also difficult to measure, it is known as unknown loss. Unknown loss of business is the supply generated in the process, it is also known as business losses.

Power Transmission and Distribution operation system and the components of the transmission line due to power loss mainly include three aspects: 


\section{A. Fixed loss}

Fixed loss is mainly sent by the power loss in the system substation equipment and transmission lines that occur during operation, this loss is not due to the power grid load change, is a fixed value, the loss is limited only by the size of the applied voltage "equipment and the impact of the line quality "equipment capacity and other factors.

\section{B. Variable loss}

Variable loss means a loss will change with the grid load current varies by transmission and distribution system equipment and transmission lines caused by, for example, a transformer copper loss "Device coil copper loss" line loss power transmission lines.

\section{Other losses}

For example, system operation and management personnel losses caused by improper management operations, etc.! Electricity transmission and distribution lines appear during operation loss is inevitable, but the loss is too large will not only affect the safe operation of power transmission and distribution lines, while also equipment damage, and increase the power companies in the electricity transmission and distribution lines in capital investment, the impact of the overall effectiveness of the power companies.

\section{ENERGY-SAVING TECHNOLOGIES IN ELECTRICITY TRANSMISSION AND DISTRIBUTION SYSTEM}

Power Transmission and Distribution System in the application of energy-saving technology allows the power system integration and effective use of energy, not only improves the utilization of power resources, while reducing the user's electricity expenses. But to play the energy saving technology in the power transmission and transformation system, a powerful force, the rational use of energy saving technologies need. The following is an energy-saving technology Transmission and Distribution System analysis of specific applications in power [6].

\section{A. Optimize network planning}

Take in the power transmission and distribution lines in energy saving measures, the use of energy-saving technologies, network planning needs to be based on, in order to ensure the effectiveness of energy saving technology in electric power transmission and distribution lines. In the power transmission and distribution lines to do long-term planning, develop realistic grid plan, the idea of saving energy content "technology and reasonable measures into the grid plan in order to achieve the power transmission and distribution lines running energy saving effect! grid plan should reflect the integrity of the grid forming the planning, conduct a comprehensive study of losses and problems that may arise, and to develop preventive measures to rationalize.

\section{B. Application of the new low-loss transformers equipment}

Power transmission and distribution lines transformer is an important device to run the system, accounting for a large proportion of the electricity transmission and distribution lines running total loss amount, so to achieve energy saving purpose, we should start with the transformer in the power transmission and distribution lines in the rational use of The new low-loss transformers equipment, effective control of energy consumption transformer itself. Traditional large transformer equipment and low operating power consumption, it will affect the efficiency of the entire power system, we can see the importance of transformer equipment and forces in the implementation process of saving energy, power transmission and distribution lines running In order to achieve the energy saving effect is fundamentally related departments should pay attention to the power systems of internal transformer equipment maintenance and replacement. Currently part of the electricity used in the enterprise sector in the electricity transmission and distribution lines new transformer equipment, it is an amorphous alloy core transformer with low energy consumption, "and many other advantages of small noise in the application, in line with energy saving requirements, can be used as power transmission and distribution lines running in the system of choice for transformer equipment, which can not only achieve energy saving effect, it also enables one-fifth of the original load loss of no-load operation, to ensure that electricity transmission and distribution Line continuity running an important role[7].

\section{Strengthen the distribution voltage of management control}

Voltage power distribution voltage refers to the enduser transmission, our short distance distribution voltage requirements for $10 \mathrm{KV}$. Distribution, the high-pressure side of a cell is $10 \mathrm{KV}$; a low pressure side is $220 \mathrm{~V}$ or $380 \mathrm{~V}$.

Distribution voltage over the General Assembly for the stable operation of the power transmission and distribution lines have a direct impact, is likely to cause damage to the device concerned, in order to avoid this situation, the power distribution voltage enterprises should strengthen management control. Power transmission and distribution lines in operation voltage is directly related to the strength of the power loss in transmission and distribution lines, and therefore the rational allocation of voltage is particularly necessary, select the appropriate distribution voltage can effectively avoid the control voltage is too high, reduce the power transmission and distribution lines running the loss amount, thereby reducing the amount of energy consumed to achieve power transmission and distribution systems[8].

\section{Select Transmission Line}

Levels should be expanded closure wire. The so-called wire cutoff level refers to the current per unit area of the wire through rate. When the power transmission and distribution lines running, wire closure level is higher, then it will also increase operational efficiency, with a corresponding loss in the process of running the midline will become smaller and smaller, to reduce cable loss, should improve the wire[9].

Closure level to start. When the wire closure should raise the level of life of the factors to consider wire, the wire service life is certain, thus increasing the level of wire closure to maximize the use of the wire. 
Should choose to use overhead insulated wire, insulated overhead conductor is set up in the high-altitude location of the cable, the wire is mainly used insulation materials made with a certain degree of security and stability! in the power transmission and distribution lines running Application overhead insulated wire, both to avoid operational problems caused by the staggered line, while also being able to effectively deal with a power outage caused by environmental factors and objective[10]. Not only that, to a large extent the use of overhead insulated wire can also optimize the structure of the tower, the line of laying more flexible! overhead wire insulation material in special, laying insulation can be expanded using its range, power transmission and distribution lines to save operating costs, extend the life of the wire.

\section{DCONCLUSION}

Power Transmission and Distribution losses in the amount of system equipment and transmission line transformer is relatively large, and therefore to reduce the electricity transmission and distribution facilities in the amount of loss during operation, the application of new low-loss transformers in the transmission and distribution systems, select the appropriate feature voltage and distribution lines, but everything has to be perfect in order to develop a reasonable premise grid plan, combined with the power transmission and transformation system on the basis of the actual situation of running to take appropriate energy saving measures to achieve power Transmission and Distribution system economic and stable operation of power enterprises to improve economic and social benefits.

\section{ACKNOWLEDGMENT}

The authors gratefully acknowledge the contribution of co-workers and reviewers' comments.

\section{REFERENCES}

[1] J.M.Zhang, "after finishing the comprehensive development to bring to market demand technology," Wool Technology,vol. A47,pp. 55-62, April 2000

[2] F.H. "Electric properties of carbon fiber and its application," New carbon Materials, vol.41,pp.14-19, May 1995

[3] H.Lian,X.D.Zhao, and D.S.Zhang,"Research on safety management of construction project in lean," Jou.Changsha.Dis.Voc.Tech.Co, vol. 2,pp.62-64,May 2010

[4] H.S.Zheng and S.R.Zhu, "epoxy matrix and carbon fiber monofilament Temperature-sensitive effect of its interface," Functional materials, vol.8,pp. 2079-2082, May 2012

[5] Y.X.Guo, "Modification mechanism of the surface- treated PAN based carbon fiber by electrochemical oxidation," Jour. Inorg.Mat, vol.24,pp.853-858, July 2009

[6] J.Zhu, "Effect of moisture absorption on damping and dynamic stiffness of carbon fiber/epoxy compos-ites," Jou.Mec.Scie. Tech,vol.23,pp.46-48,August 2009

[7] B.Wang,J.J.Jiang,C.Q.Kang , and Q.Xia,"The main idea of design standard of American power market and the design of electric power market of China,’Pow.Sys.Tech,vol.3,pp.24-27, July 2004

[8] L.J.Xu, "Promoting the fine management significance of power supply enterprise," Sci.Tech.Inform.Dev.Eco.vol.14,pp.24-27, May 2010

[9] M.Zeng and G.Tian, "The analysis and design of the wholesale electricity market of Latin American countries and Its Enlightenment to China ," China .Elec. Pow.News, vol.18,pp.8287, April 2009

[10] S.Pillay and U.K.Vaidya "Effects of moisture and UV exposure on liquid molded carbon fabric reinforced nylon 6 com-posite laminates," Com.Sci.Tech. vol.69,pp.839-846, April 2009 